\title{
Comparison of artificial insemination and natural service cost effectiveness in dairy cattle
}

\author{
G. E. Valergakis ${ }^{1 \dagger}$, G. Arsenos $^{1}$ and G. Banos ${ }^{1}$ \\ ${ }^{1}$ Department of Animal Production, School of Veterinary Medicine, Aristotle University of Thessaloniki, Box 393, GR-54124 Thessaloniki, Greece
}

(Received 19 April 2006; Accepted 9 October 2006)

Reproductive efficiency in the dairy herd is the most important factor for its economic success and a major concern for dairy farmers when using artificial insemination (Al) or natural service (NS). Our objectives were to estimate, compare and analyse the costs associated with breeding cattle by do-it-yourself (DIY) Al and NS and identify the factors that influence them, under typical dairy farming conditions in Greece. A simulation study was designed based on data from 120 dairy cattle farms that differed in size (range 40 to 285 cows) and milk production level (4000 to $9300 \mathrm{~kg}$ per cow per year). Different scenarios were employed to estimate costs associated directly with Al and NS as well as potentially extended calving intervals (ECI) due to Al. Results showed that bull maintenance costs for NS were $€ 1440$ to $€ 1670$ per year $(\$ 1,820$ to $\$ 2,111)$. Direct Al costs were higher than those for NS for farms with more than 30 cows and $\mathrm{ECl}$ constituted a considerable additional burden. In fact, amongst the factors that affected the amount of milk needed to cover total extra Al costs, number of days open was the dominant one. Semen, feed and heifer prices had a very small effect. When, hypothetically, use of NS bulls results in a calving interval of 12 months, Al daughters with a calving interval of 13.5 months have to produce about $705 \mathrm{~kg}$ of additional milk in order to cover the extra cost. Their actual milk production, however, exceeds this limit by more than $25 \%$. When real calving intervals are considered (13.0 v. 13.7 months for NS and Al, respectively) Al daughters turn out to produce more than twice the additional amount of milk needed. It was concluded that even under less than average management conditions, Al is more profitable than the best NS scenario. The efficient communication of this message should be a primary concern of the $\mathrm{Al}$ industry.

Keywords: artificial insemination, costs, dairy cattle, natural mating.

\section{Introduction}

Artificial insemination (Al) has found widespread use since its commercial development in the 1950s (Vishwanah, 2003). Dairy farmers world-wide appreciate the rapid genetic improvement in production and conformation traits resulting from using semen of progeny tested bulls. Furthermore, the risk of venereal disease transmission has been eliminated, the incidence of dystocia has been reduced and early breeding of virgin heifers or post-partum cows and accidents during mating are avoided. Moreover, dry cow management can be better controlled due to accurate drying off and calving dates. Breeding management has become more flexible by using semen of many bulls of the same or different breeds and, last but not least, the safety of farm personnel is ensured (Esslemont et al., 1985; Barth, 1993; Ensminger, 1993; Peters and Ball, 1995; Vishwanah, 2003).

\footnotetext{
${ }^{\dagger}$ E-mail: geval@vet.auth.gr
}

In countries of Northern Europe, Israel and Japan, dairy farmers use Al almost exclusively ( 80 to $90 \%$ ) as the service method for breeding cattle (Peters and Ball, 1995). Despite the recognised benefits of using $\mathrm{Al}$, however, a large number of dairy farmers in other parts of the world still use natural service (NS) to breed all or part of their cattle herds. In the US, Al is used exclusively by around $45 \%$ of dairy farmers (United States Department of Agriculture, 2002).

In Greece, around $47 \%$ of dairy farmers use Al exclusively to breed their cattle, $31 \%$ of them use both $\mathrm{Al}$ and NS, and $22 \%$ use NS only (Valergakis, 2000). Previously, Al was carried out by state employed technicians but now the government policy is to privatise the industry and, since the commercial Al sector is still not fully developed, the on-going trend, especially on bigger farms, is towards more frequent use of NS bulls or do-it-yourself AI (DIY-Al). Compared with using the state's Al service, this latter method is profitable for herds with more than 32 cows. In a typical 80-cow herd, annual savings exceed $€ 700$ (\$885) (Valergakis et al., 2004). 
One of the main arguments for using of NS is the higher perceived Al costs compared with those of keeping herd bulls and additional costs resulting from extended calving intervals (ECI) because of poor heat detection and conception rates when using Al (Risco, 2000; Valergakis, 2000; Cassell et al., 2002; Overton, 2005). Dairy farmers in Greece consistently under-estimate, or even ignore, the costs associated with keeping an NS bull while, at the same time, they face the financial consequences of $\mathrm{ECI}$. Most of the times, however, the latter is due to reasons irrelevant to $\mathrm{Al}$, such as inadequate nutrition and poor health management (Valergakis, 2000; Valergakis et al., 2004).

Direct comparisons of Al and NS costs are rather rare in the literature (Hillers et al., 1982; Overton, 2005). These comparisons, in order to be accurate and acceptable to dairy farmers, must reflect real farm conditions, practices and economics. For example, the recently published research by Overton (2005), based on a 1000-cow dairy unit using rotational groups of NS bulls, found little or no application in Greece where all dairy farms are smaller in size and most of the times only one bull is kept (Valergakis, 2000). The same is true for published annual costs of keeping herd bulls in the UK and the US (Esslemont et al., 1985; Johnston et al., 1987).

One commonly discussed issue is whether the breeding performance of the two service methods (Al and NS) is equal. Although there is research documenting equal or superior performance of Al (Williamson et al., 1978; Shaw and Dobson, 1996; Niles and Risco, 2002; Overton and Sischo, 2005), this is not readily accepted by most dairy farmers who, more often than not, claim better performance of NS bulls. Other research has reported an advantage of NS concerning the length of calving interval, thereby supporting the prevailing farmer opinion (Valergakis, 2000; Smith et al., 2003; Zwald, 2003; De Vries et al., 2005). Consequently, the cost of any extra 'days-open' must be included in the economic comparison of the two service methods.

Many authors have addressed the issue of the cost of 'days-open' and although some find it nonexistent (Arbel et al., 2001) or small (Holmann et al., 1984; Schmidt, 1989), most conclude that it can be significant (Britt, 1985; Williams et al., 1987; Barth, 1993; Plaizier et al., 1997; French and Nebel, 2003a; González-Recio et al., 2004). Specific economic conditions in each country or time period have a great influence on cost of 'days-open' and this should be assessed every time a study comparing Al and NS costs is conducted.

The objective of this study was to estimate, compare and analyse the costs associated with breeding cattle by DIY-AI and NS, and identify the factors that influence them, under typical dairy farming conditions in Greece.

\section{Material and methods}

Data

A simulation study was designed based on data collected from 120 dairy cattle farms (Valergakis, 2000) located in
Northern Greece, the main dairy area of the country. The average herd size was 87 cows (Holsteins, range $40-285$ cows) and the average milk production was $6443 \mathrm{~kg}$ milk per cow per year (range 4000 to $9300 \mathrm{~kg}$ ). Farm characteristics and performance, when they were classified according to service method are presented in Table 1. Calculations, based on actual farmers' practices, included: (a) direct $\mathrm{Al}$ and NS costs and (b) costs associated with extended calving intervals due to Al.

\section{Calculation of natural service costs}

Bulls used for natural service were either born on the farms that subsequently used them or were purchased from 'breeder' farms at a very young age (approx. 6 months old). They were usually sons of proven Holstein bulls. The selection criteria were mainly their dam's milk production and their sire's genetic merit. It should be noted here that only few of the 'homebred' bulls were actually homebred. Most were born to pregnant heifers imported from various European countries. Bulls were used for breeding when they were 18 months old and had reached a body weight of around $550 \mathrm{~kg}$. Smaller farms ( $<80$ cows) kept just one sexually active bull, whereas bigger farms kept two or more. Overall, no bull sired more than 80 calves per year on any of the sample farms and this was considered as the typical performance of NS bulls when Al and NS were compared. Young bulls were housed separately as yearlings but at the age of 14 to 15 months they were kept with the milking herd in loose-housing systems (straw-yards or free-stalls). On smaller farms $(<80$ cows) that kept only one bull, heifers in oestrus were either taken to the bull or all heifers designated for breeding were joining the milking herd for a period of 2 to 3 months. On bigger farms, one bull was always kept with the older heifers. Bulls tended not to receive vaccinations or breeding soundness examinations. They were kept for 2 years in order to avoid inbreeding and accidents during mating due to excess body weight. When culled, they weighted approximately $1000 \mathrm{~kg}$. Farmers' reports on low bull fertility or libido and health problems (lameness) were very rare and were not considered in this study.

Rations fed to growing bulls were calculated using National Research Council (1989) recommendations. Feeds

Table 1 Farm characteristics and performance when classified according to service method

\begin{tabular}{lcccc}
\hline \hline & Al only $^{\dagger}$ & Al only $^{\ddagger}$ & Al and NS & NS only \\
\hline No. of herds & 45 & 11 & 37 & 26 \\
Cows per herd & 86 & 76 & 94 & 82 \\
Milk production (kg per cow & 6849 & 6637 & 6410 & 5953 \\
$\quad$ per year) & & & & \\
Calving interval (months) & 13.70 & 13.55 & 13.71 & 13.01 \\
$\quad$ Services per conception & 2.2 & 2.2 & 1.9 & - \\
\hline \hline
\end{tabular}

${ }^{\dagger}$ Semen from proven sires only.

${ }^{\ddagger}$ Semen from pedigree selected sires (Greek Ministry of Agriculture). 
Cost effectiveness of $\mathrm{Al}$ and natural service in dairy cattle

used included milk replacer, starter concentrate, alfalfa hay, corn silage, wheat straw, maize grain, wheat bran, sugarbeet molasses, soya-bean meal, cottonseed cake, and mineral-vitamin supplement. Feed prices used were average market prices for each component for 2004. Land, labour, and fixed and expendable capital (minus feed) expenses were considered to be similar to dairy bulls raised for beef production, due to similar growth rates (Valergakis, 2000). These were adjusted to reflect the economic conditions prevalent in 2004 (higher expenses for land, labour and supplies, and lower interest rates).

Rations for breeding bulls were typically those for milking cows. The total amount consumed during their 2-year use was calculated as the sum of the amount needed to cover $115 \%$ of their mean maintenance requirements to reflect their breeding activity plus that required for growth to $1000 \mathrm{~kg}$ body weight. Rations and feed prices were defined similarly to those for growing bulls. Land, labour, and fixed and expendable capital (minus feed) expenses were considered to be similar to those for lactating Holstein cows (Valergakis, 2000) with the following notable exceptions: (a) 25\% lower labour expenses (bulls are not milked) were assumed, (b) fixed capital expenses for the milking machinery were not considered and (c) fixed capital expenses for the bulls were calculated for a 2-year life expectancy. All expenses were once again adjusted to economic conditions prevailing in 2004. When culled, bulls were assumed to have a $50 \%$ killing-out percentage and were sold at the average market price.

\section{Calculation of direct artificial insemination costs}

Labour and fixed (Al equipment, liquid nitrogen) as well as expendable (semen and supplies) capital expenses were included in the DIY-Al scenario, at 2004 prices. A 5-year depreciation period was used, combined with three ratios of 'number of services per conception' (1.9, 2.2 and 2.5) and two semen price levels ( $€ 15$ and $€ 25$ per straw [ $\$ 19$ to \$32]). The mean reported 'number of services per conception' ratio in the data was 2.2 (Valergakis, 2000). The two semen price levels represent current practices followed, corresponding to average and high genetic merit bulls, respectively. Hormone treatments are only occasionally used by Greek dairy farmers and expenses associated with them were not included in this study.

\section{Calculation of indirect artificial insemination costs}

Costs resulting from $\mathrm{ECl}$ were calculated using the method of French and Nebel (2003b). Briefly, this method is based on a dynamic simulation that models management practices in a dairy herd. The economic cost of extended days open (and, consequently, calving interval) is then determined for varying milk yields, prices and management practices. In the present study, parameters used included milk price, feed cost, heifer price, cull cow price, peak milk yield, number of days in milk when open cows were no longer inseminated and number of days open. Calculations considered two to six different values for each parameter. Table 2 summarises this design.
Table 2 Factors considered in the simulation study

\begin{tabular}{ll}
\hline \hline Factor & Values considered \\
\hline Milk price $(€$ per kg) & $0.35,0.38$ \\
Feed cost $(€$ per kg DM) & $0.154,0.176,0.198$ \\
Heifer price $(€$ per head) & $1200,1325,1450$ \\
Cull cow price $(€$ per kg) & $0.80,1.00$ \\
Peak milk yield $(\mathrm{kg})$ & $27.2,38.6$ \\
No. of days when inseminations stop & $180,210,240$ \\
No. of days open & $100,115,130,145,160,175$ \\
No. of services per conception & $1.9,2.2,2.5$ \\
Semen price ( $€$ per straw) & 15,25 \\
Type of NS bull ( $€$ per head per year) & 1440,1670 \\
\hline \hline
\end{tabular}

Comparison between natural service and artificial insemination costs

In cases when Al was shown to be more expensive than NS, further analysis was carried out to determine the actual size of the difference and the amount of extra milk Al daughters were required to produce to cover the additional cost. All factors that affected direct and indirect Al costs were simultaneously considered for this matter, together with the calculated cost of keeping an NS bull. In total, a $2 \times 3 \times 3 \times 2 \times 2 \times 3 \times 6 \times 3 \times 2 \times 2$ factorial arrangement of effects was considered (Table 2) yielding 15552 different scenarios.

Analysis of variance was used to estimate the effects of all the above factors on extra costs associated with Al.

Since the value of bull calves destined to be slaughtered was the same regardless of service method, the actual difference between Al and NS costs was doubled to attribute it wholly to heifers. This assumed a 1:1 male to female ratio.

In order to be easily understood by dairy farmers, potential extra costs associated with Al were expressed as the additional milk that $\mathrm{Al}$ daughters must produce to cover them. The amount of additional milk was calculated using the following equation:

$$
\begin{aligned}
& \text { amount of additional milk produced by Al daughters } \\
& =[\text { (direct Al costs - direct NS costs }) \\
& \quad+\mathrm{ECl} \text { costs }] / \text { (milk price over feed cost). }
\end{aligned}
$$

In the above equation, $\mathrm{ECl}$ refers to the extended calving interval associated with the one service compared with the other. Furthermore, $1 \mathrm{~kg}$ of extra ration DM was considered to result in $2 \mathrm{~kg}$ additional milk. The difference was ultimately expressed as the amount of milk per lactation, so it was spread over 3.5 lactations (average productive life of cows in this study).

The amount of additional milk that resulted from these calculations was compared with the actual cow performance on the farms under two calving interval scenarios: (a) actual calving intervals from the data (13.0 and 13.7 months for NS and Al respectively) (Valergakis, 2000) and (b) a hypothetical 'optimum' 12-month calving interval for 
NS and a range of calving intervals for Al. The latter is biased in favour of NS bulls but it was included in the study for those dairy farmers who, based on their experience, describe the use of NS as efficient and problem-free.

\section{Results}

\section{Direct costs}

Costs associated with NS bulls are shown in Table 3. The cost of raising a bull from birth to 18 months was calculated to be approximately $€ 940$ (\$1188), of which about $80 \%$ was associated with feed expenses. The total cost for this growing phase of a purchased bull was about $€ 1370$ (\$1732); the average price of a 6-month old bull calf bought for breeding purposes costs was $€ 650$ (\$822) and an additional $€ 42.3$ (\$53.5) interest cost was also considered. Whether homebred or purchase, a bull would yield $€ 750$ (\$948) (500 kg of carcass, €1.5 (\$1.9) per kg) when culled.

Total annual expenses during the breeding period were calculated to be $€ 1440$ (\$1820) and $€ 1670$ (\$2110) for the homebred and the purchased bull, respectively. These figures include growing phase costs and culled bull income. The difference is attributed solely to higher fixed capital expenses for the purchased bull (depreciation plus interest). When this extra cost is not taken into account, feed expenses represent about 63 to $64 \%$ of the total for both bulls.

The cost per pregnancy from NS bulls ranged from €144 to $€ 167$ ( $\$ 182$ to $\$ 211$ ) for 10 pregnancies to $€ 18$ to $€ 21$ (\$23 to $\$ 26.5$ ) when bulls were fully used (80 pregnancies), for homebred and purchased bulls, respectively (Figure 1).

The average cost per pregnancy associated with DIY-AI ranged from $€ 75$ to $€ 97$ ( $\$ 95$ to $\$ 123$ ) (Figure 1) for 10 pregnancies to $€ 40$ to $€ 62$ ( $\$ 51$ to $\$ 78$ ) for 80 pregnancies, depending on semen price (15 and 25 Euros per straw, respectively). With 80 pregnancies, semen cost represented $83 \%$ and $89 \%$ of the direct $\mathrm{Al}$ cost, respectively, while it

Table 3 Costs associated with growing (total costs) and breeding bulls; the latter is expressed as annual cost

\begin{tabular}{|c|c|c|c|c|}
\hline & \multicolumn{2}{|c|}{ Homebred bull } & \multicolumn{2}{|c|}{ Purchased bull } \\
\hline & Growing & Breeding & Growing & Breeding \\
\hline \multicolumn{5}{|l|}{ Expenses $(€)$} \\
\hline Land & 19.6 & 53.7 & 16.1 & 53.7 \\
\hline Labour & 27.5 & 49.1 & 15.3 & 49.1 \\
\hline \multicolumn{5}{|l|}{ Fixed capital } \\
\hline Housing & 37.0 & 55.7 & 24.6 & 55.7 \\
\hline Machinery & 41.2 & 102.9 & 36.6 & 102.9 \\
\hline Cattle & - & 154.6 & 692.3 & 385.8 \\
\hline \multicolumn{5}{|l|}{ Expendable capital } \\
\hline Feed & 686.7 & 813.3 & 488.2 & 813.3 \\
\hline Veterinary fees & 16.8 & 31.7 & 9.3 & 31.7 \\
\hline Other & 54.1 & 100.5 & 42.9 & 100.5 \\
\hline Interest & 60.6 & 75.6 & 43.2 & 75.6 \\
\hline Total & 943.5 & 1437.1 & 1368.5 & 1668.3 \\
\hline
\end{tabular}

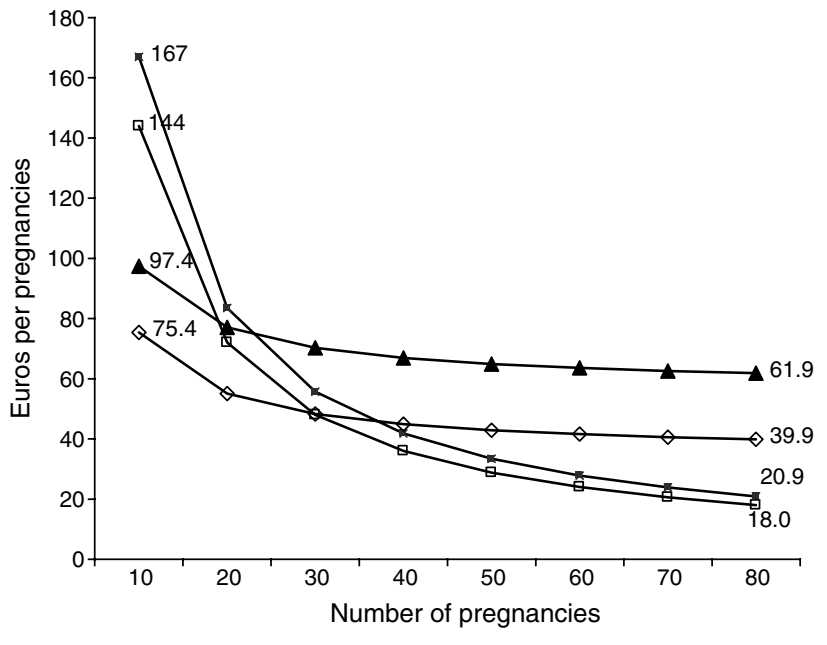

Figure 1 Natural service and artificial insemination costs per pregnancy; homebred bull $(\square)$, purchased bull $(\square)$, Al semen price $15(\diamond)$ and 25 $(\mathbf{\Lambda})$ euros per straw.

was only $44 \%$ and $57 \%$ of the total when only 10 pregnancies materialised (Figure 2). Under these circumstances, direct Al costs turned out to be higher than NS on farms with more than 20 to 25 or 30 to 35 cows, when semen was priced at $€ 25$ or $€ 15$ ( $\$ 32$ or $\$ 19$ ) per straw, respectively (Figure 1). Direct cost of Al daughters was between $€ 38$ and $€ 88$ (\$48 and \$111.2), higher than their NS counterparts depending on feed and milk prices. This means the Al daughters have to produce between 125 and $350 \mathrm{~kg}$ of milk per lactation more than the NS counterparts in order to cover this extra direct cost.

Indirect costs due to extended calving intervals

Mean costs resulting from $\mathrm{ECl}$ (indirect $\mathrm{Al}$ costs) ranged from €2.9 (\$3.7) per day when the calving interval was

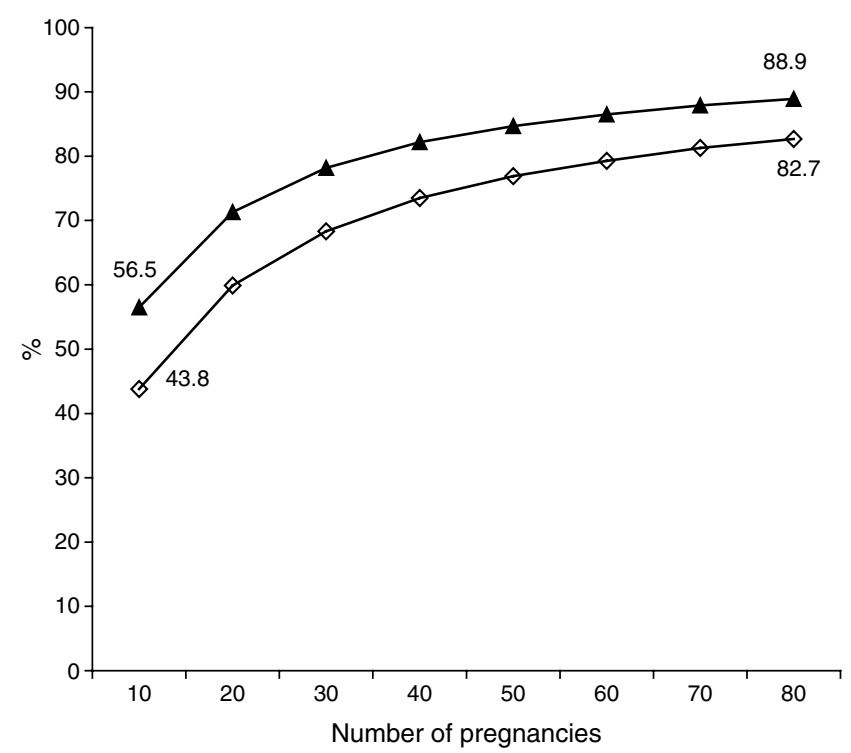

Figure 2 Proportion of direct Al cost accounted for by semen price; Al semen price $15(\diamond)$ and 25 euros per straw $(\boldsymbol{\Lambda})$. 
380 days, (100 days open), to $€ 8.6$ ( $\$ 11)$ per day when the calving interval was 455 days (175 days open) (Figure 3). When $\mathrm{Al}$ results in $\mathrm{ECl}$, the costs associated with $\mathrm{ECl}$ must be added to those from the direct comparison of $\mathrm{Al}$ and NS. This increases the amount of the additional milk that Al daughters must produce.

All factors examined had a significant effect on the amount of milk needed to cover total extra Al costs (Table 4), with number of days open having the largest effect. Number of days in milk when open cows were no longer bred (a management decision), ranked second, closely followed by peak milk yield. Interestingly, all other factors, although significant, had a relatively small effect.

Semen price, number of services per pregnancy and type of NS bull (homebred or purchased) together constituted the costs associated with the service method of choice (Al or NS). The extra cost associated with the service method per se (direct Al costs - direct NS costs) accounted, on average, for only $11 \%$ of the total breeding cost. Such costs ranged from $2 \%$ to $29 \%$ (Figure 4), depending on calving interval. Costs associated with ECl, as a consequence of prolonged days open, constituted the major proportion of the extra costs of using Al.

Amount of additional milk needed to cover the extra costs The average amount of additional milk needed from Al daughters to cover total extra costs of using Al for various calving intervals, together with the $95 \%$ confidence interval, is shown in Figure 5 . When the real calving intervals were considered (13.0 and 13.7 months for NS and Al, respectively), the additional milk needed per lactation in order to cover the extra costs of using Al was $441 \mathrm{~kg}$.

As NS bulls were assumed to achieve 12-month calving intervals, a difference of more than $1,100 \mathrm{~kg}$ of milk per lactation was needed to cover the extra costs when Al calving intervals were longer than 14 months. However,

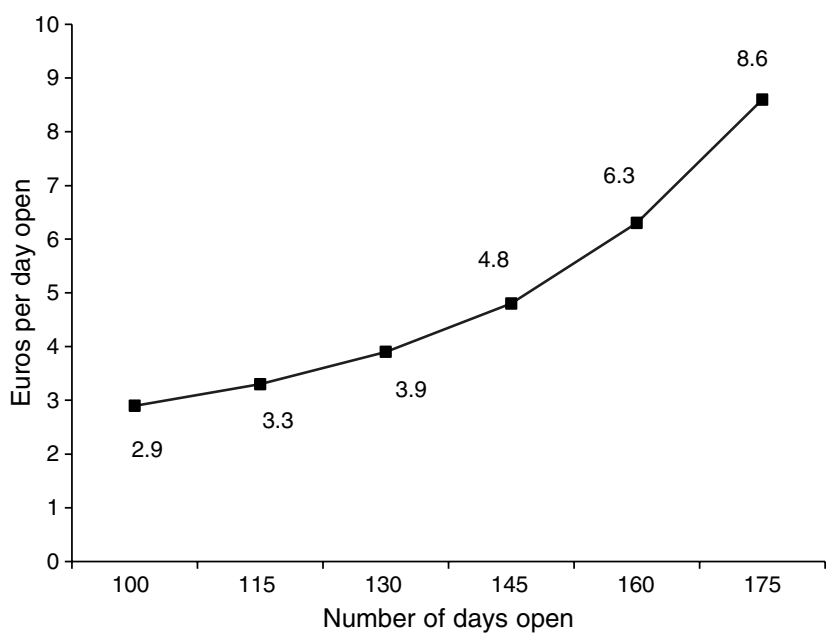

Figure 3 Average cost of extended calving interval as a consequence of prolonged days open.
Table 4 Factors affecting the amount of additional milk required by Al daughters to recover the extra cost of using $A l$ and corresponding adjusted Wald statistic (F); all factors were statistically significant $(\mathrm{P}<0.05)$

\begin{tabular}{lr}
\hline \hline Factor & \multicolumn{1}{c}{$F$} \\
\hline Days open & 94303.8 \\
No. of days when inseminations stop & 2383.7 \\
Peak milk yield & 2037.1 \\
Milk price & 1284.1 \\
Cull cow price & 1009.1 \\
Semen price & 297.2 \\
Heifer price & 243.8 \\
Services per conception & 31.5 \\
Feed cost & 6.7 \\
Type of NS bull & 5.2 \\
\hline \hline
\end{tabular}

about $700 \mathrm{~kg}$ were enough when the Al calving interval was 13.5 months ( 410 days).

In our data, cows sired by proven Al semen produced an average of $896 \mathrm{~kg}$ of milk per year more than daughters of NS bulls (Table 1). When calving intervals were kept within reasonable limits, Al was more profitable than NS.

\section{Discussion}

Farmers often complain about the escalating cost of production. However, most of them underestimate or even ignore the cost of keeping NS bulls on their farms. Even if they consider relevant expenses for labour, housing, machinery and supplies as small, still $\frac{3}{4}$ of the total expenses of keeping NS bulls is due to feed and depreciation (Valergakis, 2000).

One of the reasons for the rapid expansion of $\mathrm{Al}$ in the past was its lower cost compared with NS in small farms. This is still true but nowadays there are not many small farms left. Nevertheless, when the bull to cow ratio is close to 1:40 (i.e. 40 pregnancies are expected per bull) direct Al and NS costs are similar when semen prices are $€ 11$ to $€ 13.6$ (\$14 to \$17) per straw. This holds true either for small farms ( $<40$ cows) using a single NS bull, or bigger farms using more than one NS bulls, or, primarily, for farms that use clean-up bulls ( $31 \%$ of the farms in this study). Cows

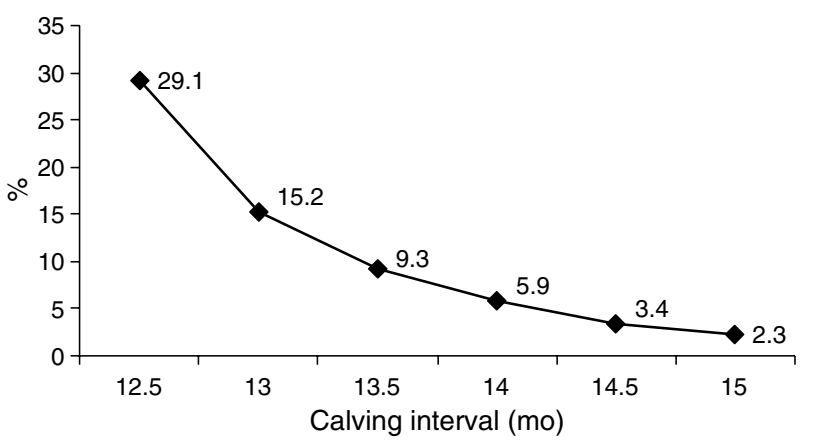

Figure 4 Proportion of total breeding-associated costs accounted for by the service method of choice depending on calving interval. 


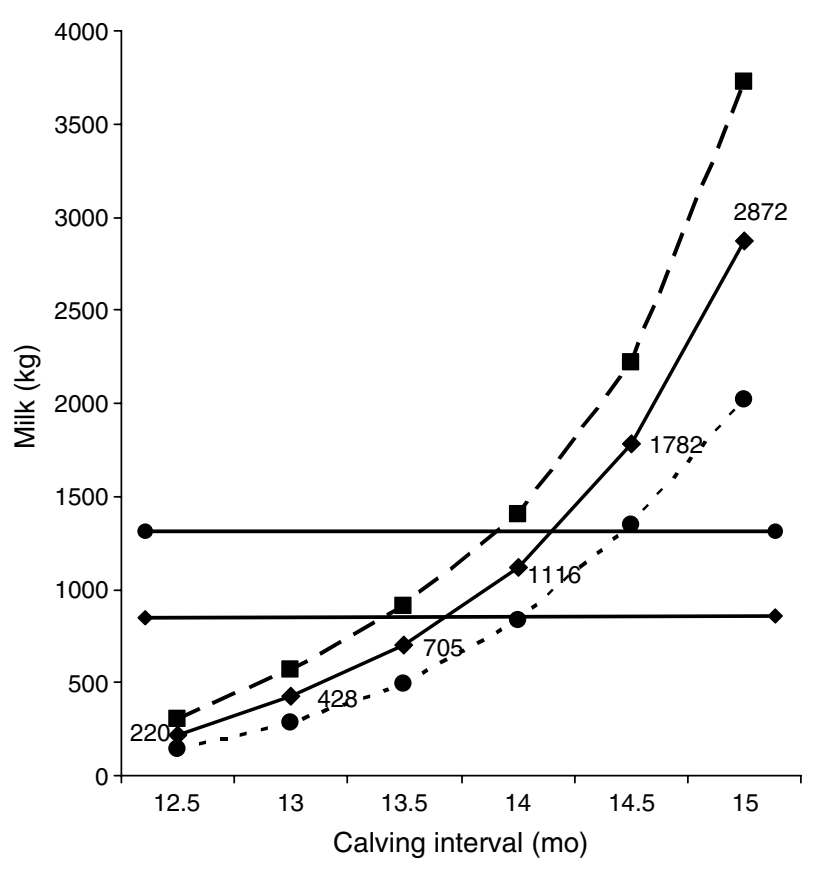

Figure 5 Average (middle solid line) and 95\% confidence interval (upper and lower dotted lines) of the amount of additional lactation milk yield required by $\mathrm{Al}$ daughters to recover the extra cost of using $\mathrm{Al}$, depending on their calving interval; actual superiority of Al daughters observed in Greece $(\bullet)$ and the USA (๑); NS calving interval was assumed to be 12 months.

requiring four or more inseminations to conceive should be less than $15 \%$ of the herd (Archbald, 1993). If a clean-up bull is used for $20 \%$ of the cows in the herd then, for semen priced at $€ 15$ or $€ 25$ ( $\$ 19$ or $\$ 32$ ) per straw, Al becomes less expensive than keeping an NS clean-up bull in herds with less than 150 or 100 cows, respectively. Most Greek farms are smaller than this. If cheaper semen, either from Holstein or other dairy or beef breed bulls is used for those 'low fertility' cows, Al can become even more competitive in farms that use clean-up bulls.

The present study considered only an Al scenario where farmers themselves administer semen to their cows. This is the current trend in the country gradually replacing the previous system where inseminators were state employees. Commercial Al is still in its infancy in Greece and although it seems profitable for very small herds, its profitability is questionable in medium sized farms (70 to 200 cows), when dairy managers have the time to personally assume the task. The 'do-it-yourself' option is therefore considered the most suitable under Greek conditions.

Artificial insemination is more expensive for farms that make good use of NS bulls ( 80 pregnancies per year). The difference between homebred and purchased NS bull is small and if the latter results in less inbreeding and better herd genetics, it is certainly a worthy choice.

On farms where Al is more expensive than NS, the major part of the extra cost results from potentially extended calving intervals (a consequence of increased number of days open). Large-scale surveys confirm this assumption, reporting calving intervals of 13.0 v. 13.7
(Valergakis, 2000), 13.8 v. 14.1 (Zwald, 2003) and 13.6 v. 14.1 months (Smith et al., 2003) for NS and Al, respectively. Others, however, report equal or superior performance of Al (Williamson et al., 1978; Shaw and Dobson, 1996; Niles and Risco, 2002; Overton and Sischo, 2005), suggesting that calving interval is not a matter of service method per se but mostly a management issue. When using $\mathrm{Al}$ and the effective pregnancy rate is more than $25 \%$, the use of NS bulls does not improve net income per cow significantly (Risco, 2000). In any case, the common belief in Greece that NS bulls generally achieve 12-month calving intervals proves to be a myth (Valergakis, 2000). Moreover, when NS bulls achieve shorter calving intervals than $\mathrm{Al}$, the difference tends to be less than 1 month (Valergakis, 2000; Smith et al., 2003; Zwald, 2003).

The cost of extra days open resulting from the method used (French and Nebel, 2003b) in this simulation, ranging from $€ 2.9$ to $€ 8.6$ ( $\$ 3.7$ to $\$ 10.9$ ) (the mean cost per day open was €5.0 [\$6.3]) is higher than those most recently calculated either by Plaizier et al. (1997) (Canadian $\$ 4.7$ per day, €0.72 /Canadian \$) or González-Recio et al. (2004) (US \$4.9 per day, \$0.82/US \$). It is even higher than that calculated by French and Nebel (2003a) using the same method (about US $\$ 2.0$ per day open). It seems that current market conditions in Greece have a greater impact on cost of days open than in Canada, Spain or the US, making extended calving intervals even less desirable and stressing the need for country- and time-specific calculations.

Number of days in milk when open cows are no longer inseminated, a decision closely related with the culling policy of the farm, was the factor with second largest effect on higher Al costs in this study. It is clear that farmers need to develop and follow a well thought-out plan on this issue.

Factors that usually attract the attention of dairy farmers (milk, cull cow, semen, heifer and feed prices) had a statistically significant but very small effect on the comparison between $\mathrm{Al}$ and NS costs in this study. Plaizier et al. (1997) found that milk, carcass, feed and replacement heifer prices did not significantly affect the cost of days open. These factors do not have to be considered as primary ones in the decision-making process concerning the choice of service method.

In the present study, daughters of proven Al sires were producing $896 \mathrm{~kg}$ more milk per cow per year than daughters of NS bulls. Norman et al. (2002) and Cassell et al. (2002) reported differences of the magnitude of 360 to more than $500 \mathrm{~kg}$, respectively. Other researchers report considerably greater differences of 1221 (Zwald, 2003), 1464 (Smith et al., 2003) and 1333 (De Vries et al., 2005) $\mathrm{kg}$ of milk, in favour of farms using Al exclusively (Figure 6). The higher overall milk production in US farms considered in the latter studies is most probably the source of the difference between them and the Greek dairy farms. Selection for milk production is additive by nature and will eventually have the same effect in Greece. The advantage of Al daughters over their NS counterparts is expected to increase in the future. Combined selection for milk 


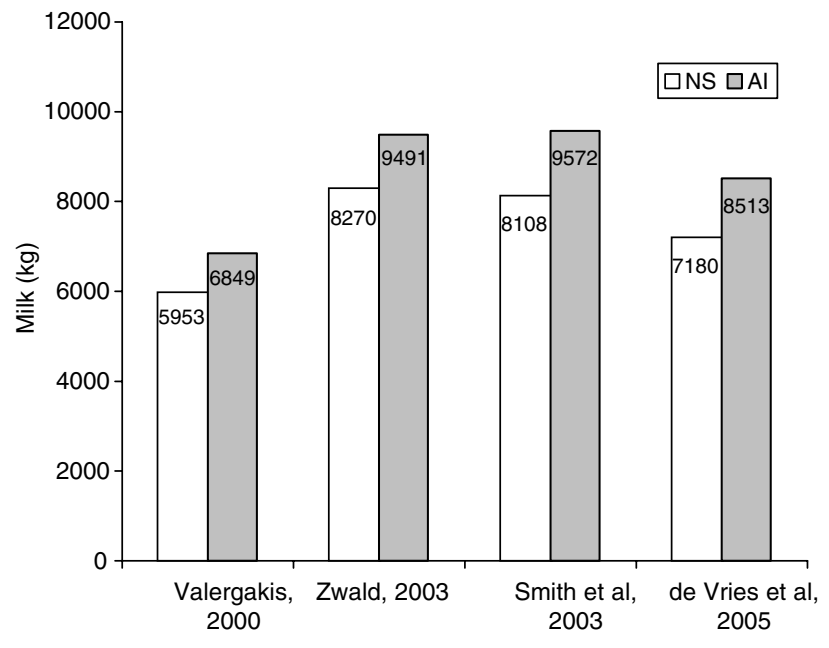

Figure 6 Milk production in farms using exclusively AI or NS.

production and fertility will provide Al an additional advantage. Only when the bulls used for NS are of the same genetic merit with those that are sampled for $\mathrm{Al}$ can the economic losses be reduced (Risco, 2000). Because of the size and complexity of most progeny-testing schemes currently catering to the international Al semen supply, this is not expected to ever be the case. Actually, NS breeding would first have to play catch up with $\mathrm{Al}$, given the existing difference, before becoming competitive. Results from the present study further corroborate this assertion.

Using the difference of $896 \mathrm{~kg}$ of milk between $\mathrm{Al}$ and NS farms calculated in this study and considering the least favourable scenario for Al (NS bulls achieving a 12-month calving interval), Al was always more profitable when the calving interval was 13 months or lower (Figure 5). Furthermore, Al was more profitable in $97 \%$ of the cases examined when the calving interval was 13.5 months (Figure 5). In the future, the difference between Al and NS farms in Greece is likely to follow the US pattern, that is, to average more than $1300 \mathrm{~kg}$ of milk in favour of Al farms (Smith et al., 2003; Zwald, 2003; De Vries et al., 2005). When that happens, Al will be more profitable than NS in all herds with calving interval shorter than 14 months and even in $94 \%$ of the herds with a calving interval of 14 months (Figure 5). Under Greek conditions, the expected difference of 1000 to $1300 \mathrm{~kg}$ between Al and NS farms will result in 6 to $7 \%$ lower production costs and a 30 to $35 \%$ increase in profits (Valergakis and Banos, 2004).

It appears that, under Greek conditions, when the difference in calving intervals between NS and Al farms is kept below 1.5 to 2.0 months, $\mathrm{Al}$ is the most profitable option. Better reproductive management will present even more benefits to dairy farmers that use Al.

It must be noted that, in all cases, none of the other benefits of Al or the potential problems of NS was given a monetary value in this study. The former includes selection for better conformation, increased milk components, lower somatic cell counts, improved fertility, longer productive life, and easy calving sires etc. All have a positive effect on dairy farming profitability (Esslemont et al., 1985; Barth, 1993; Ensminger, 1993; Peters and Ball, 1995; Vishwanah, 2003). On the contrary, NS means increased risk of venereal disease transmission, management problems with early-bred heifers and unknown drying-off and calving dates, increased frequency of dystocia, accidents during mating, possible low bull fertility or libido and bull morbidity/early culling, all negatively affecting profitability (Esslemont et al., 1985; Barth, 1993; Ensminger, 1993; Peters and Ball, 1995; Vishwanah, 2003). Moreover, farm personnel safety issues can never be over-emphasised.

\section{Conclusion}

Even under less than average management conditions, $\mathrm{Al}$ is more profitable than the best NS scenario. The efficient communication of this message should be a primary concern of the Al industry. The documented profitability of genetically superior cattle must be comprehensively presented to dairy farmers so that they can truly make informed decisions. The Greek dairy industry can have a considerable benefit from lower production costs and increased profits.

\section{References}

Archbald LF 1993. Dairy herd reproductive efficiency. In Current veterinary therapy 3, food animal practice (ed. JL Howard), pp. 798-800. WB Saunders Company, Philadelphia, PA.

Arbel $R$, Bigun $Y$, Ezra $E$, Sturman $H$ and Hojman D 2001. The effect of extended calving intervals in high lactating cows on milk production and profitability. Journal of Dairy Science 84, 600-608.

Barth AD 1993. Factors affecting fertility with artificial insemination. In Female bovine infertility (ed. WF Braun and RS Youngquist), Veterinary clinics of North America: food animal practice 9, 275-289.

Britt JH 1985. Enhanced reproduction and its economic implications. Journal of Dairy Science 68, 1585-1592.

Cassell BG, Jobst SM, McGilliard ML and Pearson RE 2002. Evaluating sire selection practices using lifetime net income functions. Journal of Dairy Science 85, 3492-3502.

De Vries A, Steenholdt C and Risco CA 2005. Pregnancy rates and milk production in natural service and artificially inseminated dairy herds in Florida and Georgia. Journal of Dairy Science 88, 948-956.

Ensminger ME 1993. Dairy cattle science. Interstate Publishers Inc., Danville, IL.

Esslemont RJ, Bailie JH and Cooper MJ 1985. Fertility management in dairy cattle. Collins, London, UK.

French PD and Nebel RL 2003a. The simulated economic cost of extended calving intervals in dairy herds and comparison of reproductive management programs. Journal of Dairy Science 86, (suppl. 1) 54.

French PD and Nebel RL 2003b. Reproductive program cost analysis. http:// oregonstate.edu/dept/animal-sciences/dairy/repro.htm

González-Recio 0, Pérez-Cabal MA and Alenda R 2004. Economic value of female fertility and its relationship with profit in Spanish dairy cattle. Journal of Dairy Science 87, 3053-3061.

Hillers JK, Thonney SC and Gaskins CT 1982. Economic comparison of breeding dairy cows artificially versus naturally. Journal of Dairy Science 65, 861-865.

Holmann FJ, Shumway CR, Blake RW, Schwart RB and Sudweeks EM 1984. Economic value of days open for Holstein cows of alternative milk yields with varying calving intervals. Journal of Dairy Science 67, 636-643.

Johnston RP, Sendelbach AG and Howard WT 1987. The annual cost of a dairy sire. University of Wisconsin Extension Publication, Madison, USA. 
National Research Council 1989. Nutrient requirements of dairy cattle, sixth revised edition. National Academy Press, Washington, DC.

Niles D and Risco CA 2002. Seasonal evaluation of artificial insemination and natural service pregnancy rates in dairy herds. Compendium for the Continuing Education of Practicing Veterinarians 24, S44.

Norman HD, Powell RL, Wright JR and Slatter CG 2002. Timeliness and effectiveness of progeny testing through artificial insemination. Journal of Dairy Science 86, 1513-1525.

Overton MW 2005. Cost comparison of natural service sires and artificial insemination for dairy cattle reproductive management. Theriogenology 64 , 589-602.

Overton MW and Sischo WM 2005. Comparison of reproductive performance by artificial insemination versus natural service sires in California dairies. Theriogenology 64, 603-613.

Peters AR and Ball PJH 1995. Reproduction in cattle. Blackwell Science Ltd, Oxford, UK.

Plaizier JCB, King GJ, Dekkers JCM and Lissemore K 1997. Estimation of economic values of indices for reproductive performance in dairy herds using computer simulation. Journal of Dairy Science 80, 2775-2783.

Risco CA 2000. Management and economics of natural service sires on dairy herds. In Topics in bull fertility (ed. PJ Chenoweth), International Veterinary Information Service, Ithaca NY (www.ivis.org).

Schmidt GH 1989. Effect of length of calving intervals on income over feed and variable costs. Journal of Dairy Science 72, 1605-1611.

Shaw C and Dobson H 1996. Reproductive and financial impact of a do-it yourself artificial insemination program compared with keeping a bull. Veterinary Record 139, 594-597.
Smith JW, Ely LO, Gilson WD and Graves WM 2003. Effect of artificial insemination vs natural service breeding on production and reproduction parameters. Journal of Dairy Science 81, (Suppl. 1) 357.

United States Department of Agriculture 2002. Part I: reference of dairy health and management in the United States, 2002. http://nahms.aphis.usda.gov/ dairy/dairy02/Dairy02Pt1.pdf

Valergakis GE 2000. Farm conditions and methods of dairy cattle production in relation to the dairy farming productivity and profitability. Doctoral thesis, Faculty of Veterinary Medicine, Aristotle University of Thessaloniki, Greece.

Valergakis GE and Banos G 2004. Investment plan for decreasing the cow milk production cost. Journal of the Hellenic Veterinary Medical Society 55, 11-20.

Valergakis GE, Banos G, Arsenos G and Zioganas C 2004. Comparative study of natural service and artificial insemination costs in dairy cattle. Proceedings of the fourth Panhellenic Congress of Food Animal Veterinary Medicine, Thessaloniki, Greece, pp. 179-180.

Vishwanah R 2003. Artificial insemination: the state of the art. Theriogenology $59,571-584$.

Williams CB, Oltenacu PA, Bratton CA and Milligan RA 1987. Effect of business and dairy herd management practices on the variable cost of producing milk. Journal of Dairy Science 70, 1701-1709.

Williamson NB, Morris RS and Anderson GA 1978. Pregnancy rates and nonreturn rates following artificial and natural breeding in dairy herds. Australian Veterinary Journal 54, 111-120.

Zwald N 2003. Does the extra effort of A.I. pay off? Hoard's Dairyman Supplement, 25 October, p.11. 